Research Article

\title{
Studies on Haematological and some Serum Biochemical Changes by Oral Administration of Gossypol from Cotton Seed Cake in Rabbits
}

\author{
Altaf Mahmood ${ }^{1^{*}}$, Muhammad Athar Khan ${ }^{2}$, Saima Parveen $^{3}$, Tanveer Hussain ${ }^{4}$ and Ayesha Azad ${ }^{5}$ \\ ${ }^{1}$ Directorate of Animal Disease Diagnostic, Reporting and Surveillance, Livestock and Dairy Development \\ Department, Govt. of Punjab, Chakwal, Pakistan; ${ }^{2}$ Department of Epidemiology and Public Health, University \\ of Veterinary and Animal Sciences, Lahore, Pakistan; ${ }^{3}$ Department of Biology, Faculty of Science and Technology, \\ Virtual University of Pakistan, Lahore, Pakistan; ${ }^{4}$ Department of Molecular Biology and Biotechnology, Faculty of \\ Science and Technology, Virtual University of Pakistan, Lahore, Pakistan; ${ }^{5}$ Poultry Research Institute, Livestock and \\ Dairy Development Department, Govt. of Punjab, Pakistan.
}

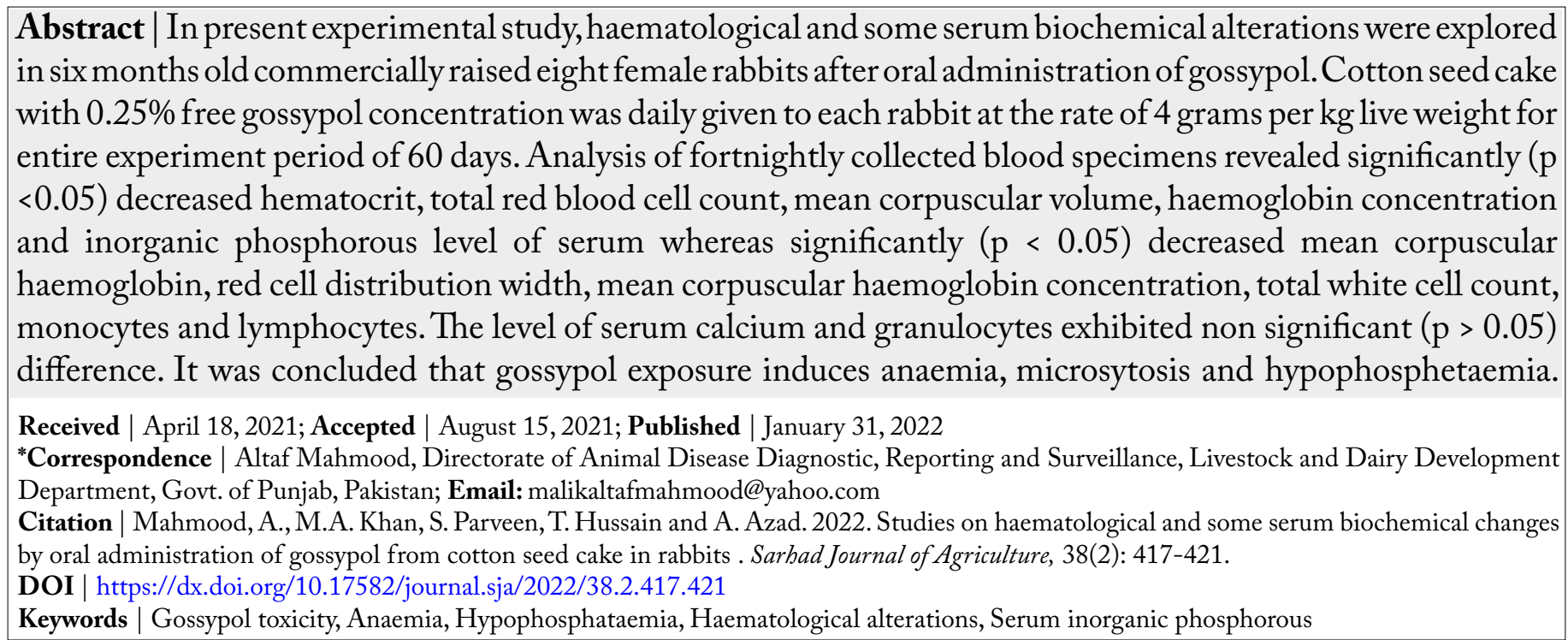

\section{Introduction}

$\mathrm{C}$ otton seed cake is among major component of livestock feed in cotton growing areas. Despite being a potential protein source, its usage is confined because of gossypol $\left(\mathrm{C}_{30} \mathrm{H}_{30} \mathrm{O}_{8}\right)$, a naturally occurring polyphenolic dialdehyde present mostly in pigment gland of the cotton plant and provide protection against the insect damage (Datta et al., 2017). Free form of gossypol is toxic whereas no toxicity has been associated with its bounded form. Its toxic effects have been recorded in non-ruminants and ruminants (Gadelha et al., 2014). Ruminants have however the ability to detoxify the free gossypol concentration by binding it with ruminal microbial proteins (Rehemujiang et al., 2019). But this ability is reduced when gossypol intake exceeds rumen detoxification capacity (Morgan, 2015). According to recommendations of European Food Safety Authority (EFSA), maximum permitted level (MPL) of gossypol for dairy cattle is $130 \mathrm{mg} / \mathrm{kg}$ diet or $4.4 \mathrm{mg} /$ $\mathrm{kg}$ body weight per day. Subclinical erythrocyte fragility is recorded in dairy cattle at dose level of $13 \& 18 \mathrm{mg} / \mathrm{kg}$ body weight (Knusten et al., 2017). Gossypol inhibits erythropoiesis by binding with iron. Gossypol iron complex is formed rendering iron June 2022 | Volume 38 | Issue 2 | Page 417 
unavailable for absorption leading to iron deficit and consequently anaemia (Chen et al., 2016). Gossypol also increases erythrocyte fragility and stimulates erythropoiesis by enhancing cystosolic $\mathrm{Ca}^{2+}$ activity leading to cell membrane scrambling, contraction and haemolysis (Tang et al., 2017). This experiment was designed to explore the haematobiochemical aspects of gossypol toxicity in female rabbits.

\section{Materials and Methods}

\section{Experimental animals}

A group of commercially raised eight female rabbits of six months age was reared at university of veterinary and animal sciences Lahore for a period of sixty days. Fresh spinach, cucumber carrots and cabbage were fed to them with adequate quantity of clean water. Cotton seed cake having $0.25 \%$ free gossypol content was orally administered to each rabbit daily at the rate of 4 grams per $\mathrm{kg}$ live weight for a period of 60 days.

\section{Quantification of free gossypol in cotton seed cake}

Free gossypol content in cotton seed cake was quantified according to official method ba-7-58 recommended by society of American oil chemists (Karishma et al., 2016). Five solutions were prepared for use in this method including 70\% aqueous acetone (700 $\mathrm{ml}$ reagent grade acetone $\& 300 \mathrm{ml}$ distilled water); $80 \%$ aqueous isopropyl alcohol $(800 \mathrm{ml}$ reagent grade isopropyl alcohol \& 200ml distilled water); $10 \%$ thiourea (10 grams reagent grade thiourea in distilled water making it to $100 \mathrm{ml}) ; 1.2 \%$ hydrochloric acid (106ml of concentrated hydrochloric acid $/ 37 \%$ \& distilled water to a volume of $1000 \mathrm{ml}$ ) and Gossypol standard solution for free gossypol. For preparation of gossypol standard solution, $27.9 \mathrm{mg}$ of primary standard quality gossypol acetic acid, $100 \mathrm{ml}$ reagent grade acetone, $50 \mathrm{ml}$ reagent grade acetic acid glacial and $75 \mathrm{ml}$ distilled water were added in $250 \mathrm{ml}$ volumetric flask and then diluted to the volume with reagent grade acetone. $50 \mathrm{ml}$ of the solution was then placed in $250 \mathrm{ml}$ volumetric flask to which $100 \mathrm{ml}$ reagent grade acetone and $60 \mathrm{ml}$ distilled water were added, diluted to the volume with reagent grade acetone and thoroughly mixed. This standard solution contained $0.025 \mathrm{mg}$ gossypol per $\mathrm{ml}$ and was stable for 24 hours if prevented from sunlight exposure.

2 grams of ground cotton seed cake was placed in $250 \mathrm{ml}$ Erlenmeyer flask whose bottom was covered with glass beads. $50 \mathrm{ml}$ of $70 \%$ aqueous acetone solution was added; flask was stoppered with an air tight proof glass stopper and shaken for one hour on mechanical shaker. Mixture was then filtered using filter paper of medium retentively. First $5 \mathrm{ml}$ was discarded and remaining filtrate was collected in $100 \mathrm{ml} \mathrm{Er-}$ lenmeyer flask. $10 \mathrm{ml}$ of two aliquots were separately pipetted into $25 \mathrm{ml}$ volumetric flasks designated as $\mathrm{A}$ and B. $2 \mathrm{ml}$ of aniline, 2 drops of $10 \%$ thiourea and $10 \mathrm{ml}$ of $70 \%$ aqueous acetone were then pipetted into another $25 \mathrm{ml}$ volumetric flask designated as $\mathrm{C}$ which was used as reagent blank. In flask $A$, one drop of $1.2 \mathrm{~N}$ hydrochloric acid solution and $0.10 \mathrm{ml}$ of $10 \%$ thiourea were added and diluted with $80 \%$ isopropyl alcohol to the volume. In flask $\mathrm{B}, 2 \mathrm{ml}$ aniline, two drops of $10 \%$ thiourea and one drop of $1.2 \mathrm{~N}$ hydrochloric acid solutions were added. Flask $\mathrm{B}$ and $\mathrm{C}$ were placed in water bath for 30 minutes at $100 \mathrm{C}^{\circ}$. Ten $\mathrm{ml}$ of $80 \%$ aqueous isopropyl alcohol was added to both flasks after removing them from water bath. Flasks were then cooled to room temperature using another water bath and $80 \%$ aqueous isopropyl was added to dilute their contents to the volume. Absorbance of A was estimated at $440 \mathrm{~nm}$ using $80 \%$ isopropyl alcohol to adjust the spectrophotometer at zero absorbance. Absorbance of $B$ was estimated at $440 \mathrm{~nm}$ using $C$ to adjust the instrument at zero absorbance. Corrected absorbance was calculated as under:

\section{Corrected Absorbance $=$ Absorbance of solution $B-$ Absorbance of solution $A$}

\section{Calibration}

Two sets of standard gossypol aliquots of 2, 4, 6, 8 and $10 \mathrm{ml}$ were pipetted into $25 \mathrm{ml}$ volumetric flasks designated as A \& B. $10 \mathrm{ml}$ of $70 \%$ aqueous acetone solution was pipetted into $25 \mathrm{ml}$ volumetric flask to which $2 \mathrm{ml}$ aniline and two drops of $10 \%$ thiourea were added and designated as $\mathrm{C}$ to use as reagent blank. One drop of $1.2 \mathrm{~N}$ hydrochloric acid and two drops of $10 \%$ thiourea were added into $\mathrm{A}$ and then diluted to the volume with $80 \%$ aqueous isopropyl alcohol. Into B, 2 $\mathrm{ml}$ aniline, two drops of $1.2 \mathrm{~N}$ hydrochloric acid and two drops of $10 \%$ thiourea solution were added. B and $\mathrm{C}$ were placed in water bath at $100 \mathrm{C}^{\circ}$ for half hour, allowed to cool to room temperature, cooled to room temperature and $80 \%$ was then added to the volume. Absorbance of $\mathrm{A} \& \mathrm{~B}$ was determined using $\mathrm{C}$ as blank whereas corrected absorbance for both gossypol standard aliquots was calculated as described above. For each gossypol standard, corrected absorbance 
Table 1: Haematological and biochemical values of rabbits before (on day O) and after gossypol administration.

\begin{tabular}{|c|c|c|c|c|c|c|}
\hline \multirow[t]{2}{*}{ Parameters } & \multicolumn{5}{|l|}{ Mean \pm S.D. } & \multirow{2}{*}{$\begin{array}{l}\mathrm{P}- \\
\text { value }\end{array}$} \\
\hline & Day 0 & Day 15 & Day 30 & Day 45 & Day 60 & \\
\hline Red blood cells $\left(10^{6} / \mu \mathrm{L}\right)$ & $6.68 \pm 0.47$ & $6.28 \pm 0.297$ & $5.80 \pm 0.19$ & $5.76+0.08$ & $5.36 \pm 0.12$ & 0.0000 \\
\hline Haemoglobin (g/dL) & $11.8 \pm 1.30$ & $11.06 \pm 0.26$ & $10.37 \pm 0.45$ & $9.77 \pm 0.37$ & $9.40 \pm 0.11$ & 0.000 \\
\hline Haematocrit (\%) & $36.29 \pm 4.15$ & $33.02 \pm 1.05$ & $30.56 \pm 1.91$ & $28.84 \pm 0.83$ & $28.41 \pm 0.94$ & 0.0000 \\
\hline Mean corpuscular volume (fL) & $54.1 \pm 2.73$ & $51.9 \pm 1.06$ & $50.49 \pm 1.18$ & $49.4 \pm 1.17$ & $48.74 \pm 0.88$ & 0.000 \\
\hline Mean corpuscular haemoglobin (pg) & $17.46 \pm 0.88$ & $17.66 \pm 0.64$ & $17.92 \pm 0.45$ & $18.2 \pm 0.40$ & $18.26 \pm 0.23$ & 0.033 \\
\hline $\begin{array}{l}\text { Mean corpuscular haemoglobin } \\
\text { concentration }(\mathrm{g} / \mathrm{dL})\end{array}$ & $32.28 \pm 1.47$ & $33.56 \pm 0.83$ & $34.66 \pm 0.90$ & $35.29 \pm 0.96$ & $36.18 \pm 0.74$ & 0.000 \\
\hline Red cell distribution width (\%) & $17.33 \pm 0.79$ & $18.1 \pm 1.16$ & $18.75 \pm 1.088$ & $19.58 \pm 0.88$ & $20.1 \pm 0.78$ & 0.000 \\
\hline White blood cells $\left(10^{3} / \mu \mathrm{L}\right)$ & $3.43 \pm 1.53$ & $4.45 \pm 0.42$ & $4.58 \pm 0.52$ & $4.67 \pm 0.48$ & $4.69 \pm 0.48$ & 0.008 \\
\hline Lymphocytes $\left(10^{3} / \mu \mathrm{L}\right)$ & $2.70 \pm 1.06$ & $3.71 \pm 0.86$ & $3.97 \pm 0.53$ & $4.30 \pm 0.43$ & $4.45 \pm 0.44$ & 0.000 \\
\hline Monocytes $\left(10^{9} / \mathrm{L}\right)$ & $0.03 \pm 0.014$ & $0.04 \pm 0.02$ & $0.05 \pm 0.02$ & $0.05 \pm 0.02$ & $0.05 \pm 0.02$ & 0.002 \\
\hline Granulocytes $\left(10^{3} / \mu \mathrm{L}\right)$ & $0.71 \pm 0.59$ & $0.7125 \pm 0.97$ & $0.715 \pm 0.96$ & $0.71 \pm 0.97$ & $0.71 \pm 0.98$ & 0.967 \\
\hline Calcium (mmole /L) & $3.446 \pm 0.07$ & $3.4176 \pm 0.06$ & $3.44 \pm 0.05$ & $3.42 \pm 0.06$ & $3.4176 \pm 0.08$ & 0.866 \\
\hline Phosphorous (mg/dL) & $3.81 \pm 0.03$ & $3.72 \pm 0.049$ & $3.725 \pm 0.06$ & $3.715 \pm 0.06$ & $3.71 \pm 0.06$ & 0.012 \\
\hline
\end{tabular}

was plotted against $\mathrm{mg}$ of gossypol in $25 \mathrm{ml}$ in order to obtain a linear calibration graph which was then used to calculate a factor for computing mg of gossypol in the sample aliquots.

Factor $=\frac{\text { Quantity of gossypol }(\mathrm{mg}) \mathrm{in} 25 \mathrm{ml} \text { standard gossypol solution }}{\text { corrected absorbance of varying volumes of standard gossypol solution }}$

For all gossypol standards, average factor was calculated and mg gossypol in sample was determined by multiplying the calibration factor with sample aliquot's corrected absorbance. Percentage of free gossypol in sample aliquot was determined as mentioned below:

$$
\text { Gossypol } \%=\frac{5 \mathrm{G}}{\mathrm{WV}}
$$

$\mathrm{G}=$ Quantity of gossypol (mg) in sample aliquot; $\mathrm{W}$ is sample weight in grams and $\mathrm{V}$ is volume of sample aliquot.

\section{Collection and processing of specimens}

Blood specimens were collected fortnightly from each rabbit from ear vein puncture with sterilized needles into the vacuum tubes with and without ethyl diamine tetra acetic acid (EDTA). Non coagulated blood samples were processed for determination of haematological parameters using automated haematological analyzer following standard methods (Ghaffar et al., 2014). Serum was separated from coagulated blood samples and processed for detection of inorganic phosphorous and calcium using spectrophotometer (Mahmood et al., 2013).

\section{Statistical analysis}

Repeated measurement analysis of variance at 5\% significance was applied using SPSS 17 software.

\section{Results and Discussion}

\section{Hematological alteration}

Significant $(\mathrm{p}<0.05)$ decrease was recorded in, hematocrit, hemoglobin concentration and mean corpuscular volume. Total leukocyte count, monocytes, lymphocytes and red cell distribution width exhibited significant $(\mathrm{p}<0.05)$ increase. Non-significant $(\mathrm{p}>$ $0.05)$ alteration was recorded for granulocytes. The detailed results are presented in Table 1.

\section{Biochemical changes}

Biochemical analysis revealed significant $(p<0.05)$ decrease in serum inorganic phosphorous and non-significant $(p>0.05)$ alteration in calcium concentration of serum. Results are presented in Table 1.

Significant decrease $(\mathrm{P}<0.05)$ in red cell parameters i.e. total red cell count, hematocrit and hemoglobin as a result of gossypol treatment is indication of anemia which may be due to ability of gossypol to bind with iron thereby decrease of its availability for the erythropoiesis. The findings are complementary to (Lang et al., 2016) and contrasting (Prasad et al., 2009) with 
previous reports. Non-significant $(p>0.05)$ alteration recorded in red cell count, mean corpuscular hemoglobin concentration and mean corpuscular volume recorded in buffalo calves after gossypol treatment in a previous investigation may be associated with gossypol neutralization by microbial proteins in the rumen (Prasad et al., 2009).

Significant $(p<0.05)$ increases in red cell distribution width (RDW) with significantly decreased mean corpuscular volume (MCV) as a result of gossypol treatment is an indication of anisocytosis and microcytosis which is probably due to capacity of gossypol to bind with iron. Poikilocytosis and anisocytosis have also previously been reported after gossypol treatment (Câmara et al., 2016).

Significant $(\mathrm{p}<0.05)$ increase in leukogram parameters i.e. total white cell count, lymphocyte count and monocyte is may be due to lipid antigen like action of gossypol because of being a terpenoid aldehyde. Antigen specific naive lymphocytes are present in very small number. Repeated stimulation initiates the proliferation of activated CD4+ helper T-lymphocytes thereby differentiating them into the effecter cells function of those is mediated by the action of different cytokines. Early response initiates the secretion of interleukin-2 (IL-2) by the CD4+ helper T-cells consequently stimulating the colonal proliferation of lymphocytes (Abbas et al., 2014). The findings are contrary to a previous report (Akingbemi et al., 1994) in which leucopenia had been explored in rats after gossypol treatment but these rats were malnourished. The report concluded that gossypol treatment can cause immune-suppression when combined with protein malnutrition. The report, however, also suggested the investigation for clarification because immunoglobulin level of the gossypol treated rats was favorably comparable in the control group.

Serum inorganic phosphorous level decreased significantly $(\mathrm{p}<0.05)$ whereas serum calcium level remained non-significant $(\mathrm{p}<0.05)$. In a previous investigation, significantly decreased coefficient of total tract apparent digestibility for phosphorous was recorded in a rainbow trout as a result of increased cotton seed meal supplementation (Lee et al., 2006). Significantly $(\mathrm{p}<0.01)$ elevated magnesium and calcium whereas decline potassium concentration had been recorded in gossypol treated malnourished rats. The phosphorous level exhibited non-significant $(\mathrm{p}>$
0.05) change (Akingbemi et al., 1994).

\section{Conclusions and Recommendations}

Gossypol ingestion induced microcytosis, anaemia and hypophosphataemia in rabbits.

\section{Acknowledments}

Principle author acknowledges the Higher Education Commission of Pakistan for funding of this research project.

\section{Novelty Statement}

Haematobiochemical aspects of gossypol toxicity by experimental ingestion of cotton seed cake to adult female rabbits, have not previously been explored, according to our knowledge.

\section{Author's Contribution}

Altaf Mahmood: Designed experiment, conducted research and drafted the manuscript.

Muhammad Athar Khan: Supervised the research work.

Tanveer Hussain: Edited the manuscript.

Saima Parveen and Ayesha Azad: Analyzed the data and arranged references.

\section{Conflict of interest}

The authors declared that there is no conflict of interest.

\section{References}

Abbas, A.K., A.H. Lichtman and S. Pillai. 2014. Basic immunology: functions and disorders of the immune system: $4^{\text {th }}$ ed. Elsevier Health Sciences.

Akingbemi, B.T. and T.A. Aire.1994. Haematological and serum biochemical changes in the rat due to protein malnutrition and gossypol-ethanol interactions. J. Comp. Pathol., 111(4): 413-426. $\quad$ https://doi.org/10.1016/S00219975(05)80099-4

Câmara, A.C.L., A.M. do Vale, C.R.S. Mattoso, M.M. Melo and B. Soto-Blanco. 2016. Effects of gossypol from cottonseed cake on the blood profile in sheep. Trop. Anim. Health Prod., 
48(5):1037-1042. https://doi.org/10.1007/ s11250-016-1039-0

Chen, G., R. Wang, H. Chen, L. Wu, R.S. Ge and Y. Wang. 2016. Gossypol ameliorates liver fibrosis in diabetic rats induced by high-fat diet and streptozocin. Life Sci., 149: 58-64. https:// doi.org/10.1016/j.lfs.2016.02.044

Datta, S., R. Budhauliya, B. Das, R.Gopalakrishnan, S. Sharma, S.Chatterjee, P.S. Raju and V. Veer. 2017. Rebound of Cotton leaf curl Multan virus and its exclusive detection in cotton leaf curl disease outbreak, Punjab (India), 2015. Sci. Rep., 7(1): 17361. https://doi.org/10.1038/ s41598-017-17680-9

Gadelha, I.C.N., N.B.S. Fonseca, S.C.S. Oloris, M.M.Melo and B.Soto-Blanco.2014. Gossypol toxicity from cottonseed products. Sci. World J., pp.1-11. https://doi.org/10.1155/2014/231635

Ghaffar, A., S. Ashraf, R. Hussain, T. Hussain, M. Shafique, S. Noreen and S. Aslam. 2014. Clinicohematological disparities induced by triazophos (organophosphate) in Japanese quail. Pak. Vet. J., 34: 257-259.

Karishma, R., U.L. Sahithya, P. Suneetha, V.C.B. Naik and M.S.R. Krishna. 2016. Determination of total gossypol and free gossypol content in different varieties of $\mathrm{Bt}$ and Non Bt Cotton seed extracts by High-Performance Liquid Chromatography (HPLC). Res. J. Biotechnol., 11: 70-74.

Knutsen, H., L. Barregård, M. Bignami, B. Brüschweiler, S. Ceccatelli, M. Dinovi, L. Edler, B. Grasl-Kraupp, C. Hogstrand and L. Hoogenboom. 2017. Presence of free gossypol in whole cottonseed. EFSA J., 15(7):1-15. https://doi.org/10.2903/j.efsa.2017.4850

Lang, E., V.I. Pozdeev, H.C. Xu, P.V. Shinde, K.
Behnke,J.M.Hamdam, E.Lehnert, R.E. Scharf, F. Lang, D. Häussinger and K.S. Lang. 2016. Storage of erythrocytes induces suicidal erythrocyte death. Cell. Physiol. Biochem., 39(2): 668-676. https://doi.org/10.1159/000445657

Lee, K.J., J. Rinchard, K. Dabrowski, I. Babiak, J.S. Ottobre and J.E. Christensen. 2006. Long-term effects of dietary cottonseed meal on growth and reproductive performance of rainbow trout: three-year study. Anim. Feed Sci. Technol., 126(1-2): 93-106. https://doi. org/10.1016/j.anifeedsci.2005.06.007

Mahmood, A., M.A. Khan, M. Younus, M.A. Khan, A. Ahad, M. Ahmad, H.J. Iqbal, Z. Fatima and M. Anees. 2013. Haematological and biochemical risk factors of parturient haemoglobinuria in buffaloes. J. Anim. Plant Sci., 23(2): 364-368.

Morgan, S.E. 2015. Gossypol toxicity in livestock. DASANR., Oklahoma State University. 1(1): $1-2$.

Prasad, C.S., R.M.V.Prasad, D.S. Kumar, K.A. Kumar, P.J. Lakshmi, K. Suresh and G.K. Reddy. 2009. Effects of inclusion of cotton stem in the diets of buffalo (Bubalusbubalis) calves on haematological parameters. Buffalo Bull., 28(1): 40-43.

Rehemujiang, H.,A.Yimamu and Y.L.Wang.2019. Effect of dietary cotton stalk on nitrogen and free gossypol metabolism in sheep. Asian-australas.J. Anim. Sci., 32(2): 233-240. https://doi. org/10.5713/ajas.18.0057

Tang, C., Q. Meng, K. Zhang, T. Zhan, Q.Zhao, S. Zhang and J. Zhang, 2017. Multi-omics analyses of red blood cell reveal antioxidation mechanisms associated with hemolytic toxicity of gossypol. Oncotarget, 8(61): 103693-103709. https://doi.org/10.18632/oncotarget.21779 